\title{
Endothelin-1 plasma levels are not elevated in patients with obstructive sleep apnoea
}

\author{
F. Grimpen ${ }^{\#}$, P. Kanne ${ }^{\#}$, E. Schulz*, G. Hagenah ${ }^{\#}$, G. Hasenfuß ${ }^{\#}$, S. Andreas ${ }^{\#}$
}

\begin{abstract}
Endothelin-1 plasma levels are not elevated in patients with obstructive sleep apnoea. F. Grimpen, P. Kanne, E. Schulz, G. Hagenah, G. Hasenfuß, S. Andreas. (C) ERS Journals Ltd 2000 .

ABSTRACT: Endothelin-1 (ET-1), a potent vasoconstrictor, is released mainly by vascular endothelial cells under the influence of hypoxia and other stimuli. ET-1 is related to endothelial dysfunction, as well as arterial and pulmonary hypertension, all of which are thought to be associated with obstructive sleep apnoea (OSA).

This study evaluated venous plasma concentrations of ET-1 and noradrenaline and 24-h systemic blood pressure in 29 patients with OSA (age $=56.9 \pm 1.6 \mathrm{yrs}$; body mass index $=29.5 \pm 0.7 \mathrm{~kg} \cdot \mathrm{m}^{-2}($ mean \pm SEM) $)$. Blood samples were taken in the morning, evening and during sleep. In the same way, the patients were assessed during a night of continuous positive airway pressure (CPAP) and after 13.9 \pm 1.4 months while still on CPAP. ET-1 levels were compared to those of control subjects, who were selected from in- and outpatients and were matched to patients for age, sex, presence of arterial hypertension and coronary artery disease.

ET-1 plasma levels were not elevated in the patients compared to the controls (41.6 \pm 2.2 and $44.9 \pm 1.3 \mathrm{pg} \cdot \mathrm{mL}^{-1}$, respectively, $\left.\mathrm{p}=0.20\right)$. The ET-1 concentration did not change significantly, neither during sleep nor in the first night on CPAP therapy, nor under long-term treatment with CPAP. ET-1 neither correlated to the severity of OSA nor to that of systemic hypertension.
\end{abstract}

The results suggest that endothelin-1 does not play a crucial role in the pathophysiology of obstructive sleep apnoea.

Eur Respir J 2000; 15: 320-325.

Endothelins are peptides of 21 amino acids that are produced in a wide variety of cells. Endothelin-1 (ET-1) was isolated from vascular endothelial cells [1], whereas endothelin-2 (ET-2) and endothelin-3 (ET-3) are mainly produced within the kidney and intestine. ET-1 is released under the influence of chemical or physical stimuli, such as hypoxia or shear stress, as well as various receptor operated mechanisms. It is the most potent endogenous vasoconstrictor yet identified and seems to be intimately involved in the pathogenesis of pulmonary hypertension $[2,3]$. Whether ET-1 production is increased in arterial hypertension remains controversial though [4]. Patients with obstructive sleep apnoea (OSA) exhibit repetitive nocturnal apnoeas and hypopnoeas which result in oxygen desaturations and consecutive arousals. OSA can be successfully treated with continuous positive airway pressure (CPAP). The disease can be associated with pulmonary hypertension even in the absence of daytime hypoxaemia or concomitant lung disease $[5,6]$. In epidemiological and animal studies an association between systemic hypertension and OSA, independent of obesity, age and sex, was found [7,8]. It is therefore tempting to speculate that in OSA plasma ET-1 levels are elevated due to nocturnal desaturations and give rise to pulmonary as well as arterial hypertension. To further elucidate this hypothesis the authors' studied the influence of CPAP treatment on ET-1 plasma concentration in patients with OSA.

\section{Subjects and protocol}

\#Depts of Cardiology and Pneumology, and *Nephrology and Rheumatology, Georg-August-University, Göttingen, Germany.

Correspondence: S. Andreas

Abteilung Kardiologie und Pneumologie Georg-August-Universität Göttingen Rober-Koch-Str. 40

37075 Göttingen

Germany

Fax: 49551398918

Keywords: Continuous positive airway pressure

endothelin-1

noradrenalin

obstructive sleep apnoea

Received: April 191999

Accepted after revision September 201999

Twenty-nine consecutive subjects of both sexes that were referred to the authors' sleep laboratory with suspected OSA were studied. Inclusion criterion for this study was an apnoea/hypopnoea index (AHI) $>10$ with $<10 \%$ of apnoeas of the central type. Exclusion criteria were significant chronic obstructive lung disease as defined by a forced expiratory volume in one second/forced vital capacity $<65 \%$, myocardial infarction within 3 months of the study, chronic heart failure, and $<18$ or $>75$ yrs of age. The control group consisted of 29 in- and outpatients matched to patients in sex, age, presence of arterial hypertension and coronary artery disease, but who presented no symptoms of OSA as their history was negative for loud snoring and daytime sleepiness evaluated by questionnaire. In uncertain cases a polysomnogram was performed. In the controls, blood samples for ET-1 evaluation were taken shortly after waking in the morning.

Assessment of the patients during all three nights included polysomnography, $24 \mathrm{~h}$ ambulatory blood pressure measurement, and blood sample analysis. The first night served as baseline. The following morning an electrocardiogram, an echocardiography, and a lung function test were performed. Depending on daytime symptoms and the AHI the patients were assessed under CPAP therapy in 
the second night. These patients received a CPAP device (nCPAP System 7100 Tranquility Plus $\mathbb{R}$; Respironics, Marietta, GA, USA) for home use and were advised to use it every night. After $\sim 1 \mathrm{yr}$ these patients were re-examined in the sleep laboratory.

Blood samples were taken from an antecubital vein through an indwelling cannula each night shortly before turning off the light, during sleep, and directly after waking in the morning. The samples taken during sleep were to be obtained only at least $2 \mathrm{~h}$ after the onset of sleep and after a sustained period of obstructive apnoeas associated with arterial oxygen desaturations. During the nights with CPAP, blood was taken after $3 \mathrm{~h}$ of sleep. ET-1, noradrenaline, and adrenaline were determined from all samples; the evening and morning samples were also used for haematocrit determination.

Informed written consent was obtained from all subjects. The study was approved by the local Ethics Committee.

\section{Polysomnography}

During all three nights the patients were monitored in the following way. Electrodes for electroencephalogram (C3A2 and C4A1 of the international 10-20 system), electro-oculogram, electromyogram and electrocardiogram were positioned after skin cleansing. Airflow through the nose and mouth was recorded by thermistors, and thorax and abdominal wall motion was monitored (RT-Pak ${ }^{\mathrm{TM}}$, CNS Inc., Minneapolis, KS, USA). Arterial oxygen saturation $\left(\mathrm{Sa}, \mathrm{O}_{2}\right)$ was measured transcutaneously by pulse oximetry (Micro span 3040 G; Biochem Int., Wanheshea, WI, USA). Prior to recording, signals of thorax and abdominal wall had to be adequate in different sleep positions. During the entire night, the recording was observed on a monitor and amplification of signals was corrected when necessary. The data were stored on an optical disc by a commercially available computer system (CNS sleep lab, 1000/AMPs; Jäger, Würzburg, Germany). The polysomnogram was visually analysed in $30 \mathrm{~s}$ epochs, according to RECHTSCHAFFEN and KALES [9]. An apnoea was considered obstructive when oronasal flow was absent in the presence of abdominal or thoracic movements, and central when movements were absent as well. A hypopnoea was defined as a fall in oronasal airflow $>50 \%$ of baseline. Respiratory events were counted only when they were at least $10 \mathrm{~s}$ of duration, regardless of consecutive $\mathrm{Sa}_{\mathrm{a}} \mathrm{O}_{2}$ drop or arousal. The average minimal $\mathrm{Sa}_{2} \mathrm{O}_{2}$ was calculated as the mean nadir oxygen saturation during or following the obstructive apnoeas. OSA was diagnosed when the AHI was $\geq 10 \cdot \mathrm{h}^{-1}$. The AHI is calculated as: all apnoeas + hypopnoeas during total sleep time/total sleep time (h).

Long term blood pressure measuring, spirometry and echocardiography

Twenty-four hour ambulatory blood pressure measurement was performed using a digital oscillometric noninvasive device (Model 90207; SpaceLabs Inc., Redmond, WA, USA) which measures the arterial blood pressure at $30 \mathrm{~min}$ intervals. Recording was started in the evening simultaneously with polysomnography. The next morning the patients left the sleep laboratory. They were advised to pursue their everyday activities and to return the device in the evening so that the measurement could be terminated after $24 \mathrm{~h}$. Systemic hypertension was noted when the average blood pressure exceeded 140/90 $\mathrm{mmHg}$ as was defined by the WHO in 1994, or when the patient was on regular antihypertensive medication. Vital capacity (VC) and forced expiratory volume in one second (FEV1) are given as percentage predicted [10].

The interventricular septum, left ventricular posterior wall, left ventricular end-diastolic and left atrial diameter were evaluated by echocardiography from a left parasternal view.

\section{Serum analyses}

Immediately after obtaining the blood samples the whole blood was centrifuged and the serum was deep frozen. Later the serum was defrosted and after protein precipitation with hydrochloric acid it was sent through C2-columns ("Amprep C2"; 500 mg; Amersham International plc, Aylesbury, Bucks, UK) utilizing a vacuum pump. The columns had been conditioned with methanol and distilled water beforehand. The adsorbed molecules of ET- 1 were caught in a solution of $80 \%$ acetonitrile and $0.1 \%$ trifluoric acetic acid. After drying this fluid in a vacuum centrifuge the obtained eluate was solved in a buffer. Then the Amersham's Endothelin- $1,2\left[{ }^{125} \mathrm{I}\right]$ radioimmunoassay (Amersham Buchler $\mathrm{GmbH}$, Braunschweig, Germany) was used to determine the ET-1 level in the buffer solution. This system utilizes a high specific activity $\left[{ }^{125}\right.$ I]ET-1 tracer, together with a highly specific and sensitive antiserum. Separation of the bound antibodies from the free fraction was achieved with a second antibody preparation that was bound to polymer particles which then allowed a centrifugal separation. The next step was to measure the radioactivity in the pellets which enabled the amount of labelled ET-1 in the bound fraction to be calculated. Finally, the concentration of unlabelled ET-1 could be determined by interpolation from a standard curve.

ET-1 measurements of baseline and CPAP blood samples were conducted at the same time using the same assay; two assay sets had to be used. Follow-up data was obtained using a third assay set. Former measurements yielded an intra-assay reproducibility described by a coefficient of variation $(\mathrm{CV})$ of $4.1 \%$, and an inter-assay reproducibility of $12.1 \% \mathrm{CV}$.

Adrenaline and noradrenaline levels were assayed using the high performance liquid chromatographic (HPLC) technique with fluorescence detection after derivatization with 1,2-diphenylethylendiamine [11].

\section{Statistical analysis}

All variables are given as mean \pm SEM. The patients and the controls were compared using the unpaired Student's ttest. Two-way repeated measures analysis of variance (ANOVA) was used to compare the within and between treatment differences in ET-1 serum levels for different patient groups; where appropriate this was followed by post hoc analysis using Fisher's protected least significant difference. ANOVA was used only on the data of the follow-up patients in order to gain a valid statement of changes in the course of the study. To allow meaningful comparisons between patient groups, the authors stratified the amount of time spent with an $\mathrm{Sa}_{2} \mathrm{O}_{2}<90 \%(<25 \%$ 
versus $\geq 25 \%$ of the total sleep time). Statistical analyses were performed on a personal computer using StatView (Abacus Inc., Berkeley, CA, USA). A p-value $<0.05$ was considered statistically significant.

\section{Results}

\section{Subject characteristics}

At the time of entry to this study, 16/29 patients suffered from systemic hypertension which was treated in all cases (calcium antagonist in one, angiotensin converting enzyme inhibitor in six, diuretics in five, and $\beta$-blockers in six patients). No changes in any of these medications were made for the duration of the study. In 22 cases there was no clinical evidence of atherosclerosis; seven patients reportedly suffered from coronary artery disease. Anthropomorphic, lung function test and echocardiography data are reported in table 1 .

Of the 29 patients, 20 were examined under CPAP therapy in the second night. Of these, 19 patients received a CPAP device for home use. One patient died in the meantime, his death considered to be cardiac; another could not be reassessed due to the development of a brain tumour, and two patients left the study deliberately so that

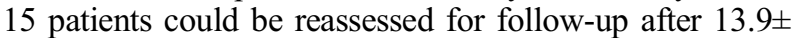
1.4 months. Compliance was determined from a CPAPdevice running time as $4.1 \pm 0.7 \mathrm{~h}$ per night.

The control group consisted of 29 matched subjects including three females. The average age of the control subjects was $56.5 \pm 1.6$ yrs. Sixteen controls suffered from systemic hypertension and seven from coronary artery disease. The average body mass index (BMI) of the controls was $27.8 \pm 0.8 \mathrm{~kg} \cdot \mathrm{m}^{-2}$, not significantly different from patient data $(\mathrm{p}=0.12)$.

\section{Long term blood pressure measurement}

No evidence of undetected systemic hypertension was found in the patients who were not on antihypertensive medication. In three patients not enough blood pressure measurements could be taken to obtain evaluable data due to sleep disturbance or refusal by the patients. The average mean arterial pressure (MAP) in the day-time after the CPAP night was not significantly different from the daytime MAP after the baseline night $(p=0.20)$ (table 2). No significant changes could be found between night-time MAP values of the baseline and the CPAP night $(\mathrm{p}=0.21)$.

Table 1. - Anthropomorphic, echocardiographic, and spirometric data

\begin{tabular}{lc}
\hline Parameter & Mean \pm SEM \\
\hline Sex F/M & $3 / 26$ \\
Age yrs & $56.9 \pm 1.6$ \\
Body mass index $\mathrm{kg} \cdot \mathrm{m}^{-2}$ & $29.5 \pm 0.7$ \\
Left atrial diameter mm & $43.1 \pm 1.2$ \\
Interventricular septum mm & $10.9 \pm 0.2$ \\
Left ventricular posterior wall mm & $10.4 \pm 0.3$ \\
Left ventricular end-diastolic diameter mm & $52.0 \pm 1.0$ \\
Vital capacity \% pred & $89.9 \pm 3.5$ \\
FEV1 \% pred & $93.3 \pm 4.7$ \\
FEV1/VC \% & $78.5 \pm 2.1$ \\
\hline
\end{tabular}

FEV1: forced expiratory volume in one second; VC: vital capacity.

MAP was statistically unchanged during the follow-up night compared to the baseline $(\mathrm{p}=0.78)$ or to the CPAP night $(\mathrm{p}=0.96)$.

There were significant correlations between the MAP during the baseline night and the minimal $\mathrm{Sa}_{\mathrm{O}} \mathrm{O}_{2}(\mathrm{r}=0.504$, $\mathrm{p}=0.009, \mathrm{n}=26)$, the AHI $(\mathrm{r}=0.425, \mathrm{p}=0.031, \mathrm{n}=26)$, and the percentage of total sleep time spent with $\mathrm{Sa}_{\mathrm{a}} \mathrm{O}_{2}<90 \%$ $(r=0.475, p=0.014, n=26)$. Stratification of baseline data by the criterion of $\mathrm{Sa}_{\mathrm{a}} \mathrm{O}_{2}$ revealed that group 1 patients $(<25 \%$ of the total sleep time spent at $<90 \% \mathrm{Sa}_{2} \mathrm{O}_{2}, \mathrm{n}=11$ ) had an average MAP of $95.6 \pm 3.0 \mathrm{mmHg}$ during the day and of $87.5 \pm 2.7 \mathrm{mmHg}$ during the night, whereas group 2 patients ( $\geq 25 \%$ of the total sleep time spent at $<90 \% \mathrm{Sa}_{2} \mathrm{O}_{2}, \mathrm{n}=14$ ) had an average daytime MAP of $97.2 \pm 2.0 \mathrm{mmHg}$, and night-time MAP of $97.9 \pm 3.7 \mathrm{mmHg}$. Thus, the authors found an insignificant increase in blood pressure during the night in group 2 , but a substantial decrease in group 1 $(\mathrm{p}=0.01)$. When the CPAP data was stratified, each group individually showed only insignificant decreases in blood pressure from day to night-time, but both groups taken together presented a trend towards a reduced MAP during the night compared to the baseline day $(\mathrm{p}=0.056, \mathrm{n}=18)$. Follow-up data revealed a significantly lower MAP in the night compared to the day. This was true for both groups together $(\mathrm{p}=0.034, \mathrm{n}=15)$ as well as for group $1(\mathrm{p}=0.016$, $\mathrm{n}=5)$, but not for group $2(\mathrm{p}=0.24, \mathrm{n}=10)$.

\section{Endothelin-1 plasma levels}

The mean values of the ET-1 measurement results are depicted in table 3. During the baseline night, the samples taken in the morning showed no significant differences with respect to the results from the controls $(41.6 \pm 2.2$ and $44.9 \pm 1.3 \mathrm{pg} \cdot \mathrm{mL}^{-1}$, respectively, $\mathrm{p}=0.20$ ), or to the samples taken during sleep $(\mathrm{p}=0.40)$ or in the evening $(\mathrm{p}=$

Table 2. - Polysomnographic and blood pressure data

\begin{tabular}{|c|c|c|c|c|}
\hline & Baseline & CPAP & $\begin{array}{l}\text { CPAP } \\
\text { follow-up }\end{array}$ & p-value* \\
\hline $\mathrm{n}$ & 29 & 20 & 15 & \\
\hline $\begin{array}{l}\text { Sleep stage } 1+2 \\
\% \text { of TST }\end{array}$ & $73.9 \pm 1.7$ & $50.3 \pm 2.5$ & $63.1 \pm 1.3$ & $<0.0001$ \\
\hline $\begin{array}{l}\text { Sleep stage } 3+4 \\
\% \text { of TST }\end{array}$ & $7.3 \pm 1.2$ & $19.5 \pm 1.5$ & $15.7 \pm 1.2$ & $<0.0001$ \\
\hline $\begin{array}{l}\text { REM sleep } \\
\% \text { TST }\end{array}$ & $18.8 \pm 1.2$ & $30.2 \pm 1.6$ & $21.3 \pm 0.9$ & $<0.0001$ \\
\hline $\begin{array}{l}\text { Total sleep time } \\
\text { min }\end{array}$ & $347 \pm 12$ & $389 \pm 12$ & $342 \pm 11$ & 0.0005 \\
\hline Sleep efficiency \% & $80.3 \pm 2.6$ & $89.7 \pm 2.4$ & $84.7 \pm 2.5$ & 0.02 \\
\hline Apnoea index $\cdot h^{-1}$ & $22.1 \pm 4.1$ & $2.8 \pm 0.4$ & $1.4 \pm 0.2$ & $<0.0001$ \\
\hline $\begin{array}{l}\text { Apnoea-hypopnoea } \\
\text { index } \cdot \mathrm{h}^{-1}\end{array}$ & $41.2 \pm 4.9$ & $11.6 \pm 1.2$ & $5.3 \pm 0.8$ & $<0.0001$ \\
\hline $\begin{array}{l}\text { Percentage of TST } \\
\text { with } \mathrm{Sa}_{\mathrm{a}, \mathrm{O}_{2}}<90 \%\end{array}$ & $29.7 \pm 4.2$ & $6.8 \pm 2.2$ & $1.2 \pm 0.4$ & $<0.0001$ \\
\hline $\begin{array}{l}\text { Number of desatu- } \\
\text { rations }<90 \% \cdot \mathrm{h}^{-1}\end{array}$ & $42.2 \pm 5.5$ & $9.4 \pm 1.1$ & $2.9 \pm 0.8$ & $<0.0001$ \\
\hline $\begin{array}{l}\text { MAP day-time } \\
\mathrm{mmHg}\end{array}$ & $96.5 \pm 1.7$ & $96.2 \pm 1.5$ & $97.0 \pm 2.1$ & 0.72 \\
\hline $\begin{array}{l}\text { MAP night-time } \\
\text { mmHg }\end{array}$ & $93.1 \pm 2.5$ & $92.8 \pm 2.7$ & $92.4 \pm 2.5$ & 0.94 \\
\hline
\end{tabular}


0.68). There was no significant difference between the samples taken during sleep and the ones taken in the evening $(\mathrm{p}=0.12)$. Under CPAP therapy the ET-1 levels during sleep and in the morning remained unchanged compared to baseline ( $\mathrm{p}=0.92$ and $\mathrm{p}=0.76$, respectively). No significant difference was found between the samples taken during sleep and those taken in the evening $(\mathrm{p}=$ $0.92)$ or in the morning $(p=0.72)$. In the follow-up night the ET-1 levels during sleep were still unchanged compared to the values of the follow-up patients during baseline $(p=0.74)$ or the CPAP-night $(p=0.76)$. Again, no significant difference was found between the samples taken during sleep and those taken in the evening $(\mathrm{p}=$ $0.50)$ or in the morning $(\mathrm{p}=0.81)$. None of the mean values for the different sampling times were significantly different from the control subjects, and ANOVA testing proved that there was no significant change of ET-1 levels in the 15 follow-up patients in the course of the study.

Comparisons between groups stratified by $\mathrm{Sa}_{\mathrm{a}} \mathrm{O}_{2}$ yielded no significant differences in the ET-1 levels, neither for the mean ET-1 level in the baseline night $(\mathrm{p}=0.25)$, nor for the sample taken during baseline sleep $(\mathrm{p}=0.97)$, which was $45.5 \pm 2.8 \mathrm{pg} \cdot \mathrm{mL}^{-1}$ for group $1(<25 \%$ of total sleep time spent at $<90 \% \mathrm{Sa}, \mathrm{O}_{2}, \mathrm{n}=13$ ) and $45.4 \pm 3.5 \mathrm{pg} \cdot \mathrm{mL}^{-1}$ for group 2 ( $\geq 25 \%$ of total sleep time spent at $<90 \% \mathrm{Sa}_{\mathrm{a}} \mathrm{O}_{2}$, $\mathrm{n}=16$ ). The stratification of the CPAP and follow-up night data yielded no significant differences concerning the ET-1 levels either.

There was no correlation between baseline morning circulating ET-1 levels and the mean arterial pressure during day-time ( $r=0.004, p=0.99, n=25)$ or night-time $(r=0.003$, $\mathrm{p}=0.99, \mathrm{n}=26)$. The patients revealed no significant correlation between baseline night ET- 1 levels and the extent of their obstructive sleep apnoea syndrome as measured by the AHI $(r=0.022, p=0.92, n=29)$, percentage of total sleep time spent with an $\mathrm{Sa}_{\mathrm{a}} \mathrm{O}_{2}<90 \%(\mathrm{r}=0.091, \mathrm{p}=0.67, \mathrm{n}=29)$, number of falls of arterial $\mathrm{Sa}_{\mathrm{a}} \mathrm{O}_{2}<90 \%$ per hour $(\mathrm{r}=0.022$, $\mathrm{p}=0.92, \mathrm{n}=29$ ), or minimum $\mathrm{S}_{\mathrm{a}} \mathrm{O}_{2}$ associated with apnoeas $(\mathrm{r}=0.194, \mathrm{p}=0.36, \mathrm{n}=29)$.

Patients who were under antihypertensive medication did not present significantly different ET-1 levels from those without such medication. This was tested for the baseline morning $(p=0.43)$, and baseline sleep $(p=0.74)$.

There was no correlation between the BMI and ET-1 plasma levels, neither for baseline morning values $(r=$ $0.057, \mathrm{p}=0.77, \mathrm{n}=29$ ), nor for baseline data gathered during sleep $(\mathrm{r}=0.378, \mathrm{p}=0.07, \mathrm{n}=29)$. Age had no significant influence on ET-1 plasma levels, neither for baseline

Table 3. - Endothelin-1 (ET-1) and noradrenaline (NA) levels

\begin{tabular}{lcccc}
\hline & Baseline & CPAP & $\begin{array}{c}\text { CPAP } \\
\text { follow-up }\end{array}$ & p-value* \\
\hline $\mathrm{n}$ & 29 & 20 & 15 & \\
ET-1 evening & $40.7 \pm 2.0$ & $43.6 \pm 2.5$ & $41.5 \pm 1.6$ & 0.31 \\
ET-1 night & $45.4 \pm 2.2$ & $43.0 \pm 2.5$ & $43.4 \pm 2.0$ & 0.79 \\
ET-1 morning & $41.6 \pm 2.2$ & $39.6 \pm 1.9$ & $43.9 \pm 1.9$ & 0.47 \\
NA evening & $245 \pm 16$ & $237 \pm 15$ & $245 \pm 26$ & 0.84 \\
NA night & $251 \pm 13$ & $252 \pm 15$ & $195 \pm 23$ & 0.004 \\
NA morning & $232 \pm 14$ & $246 \pm 15$ & $214 \pm 17$ & 0.039 \\
\hline
\end{tabular}

ET-1 is expressed in $\mathrm{pg} \cdot \mathrm{mL}^{-1}$, while NA is expressed in $\mathrm{ng} \cdot \mathrm{L}^{-1}$. *: p-values are from analysis of variance. CPAP: continuous positive airway pressure. morning ET-1 levels $(r=0.292, p=0.12, n=29)$, nor for the ET-1 levels during the baseline night $(r=0.241, p=0.26$, $n=29)$.

\section{Plasma catecholamines and haematocrit}

Plasma noradrenaline levels are given in table 3. In the baseline night, there was no significant change in noradrenaline levels during sleep compared to the evening $(p=0.91)$ or the morning $(p=0.82)$. The same was due under CPAP for the difference between the night compared to the evening $(\mathrm{p}=0.61)$ or compared to the morning sample $(p=0.28)$. Neither was there any significant difference between the nocturnal noradrenaline levels in the baseline and in the CPAP night $(\mathrm{p}=0.36)$. In the follow-up night the sample taken during sleep yielded a significantly lower value than in the baseline $(\mathrm{p}=0.011)$ or in the CPAP nights $(p=0.018)$. It also showed an insignificant trend towards lower values compared to the evening sample $(\mathrm{p}=0.065)$.

ANOVA testing proved that no significant change of the nocturnal adrenaline levels occurred in the course of the study $(\mathrm{p}=0.95)$.

Haematocrit values are reported in table 4 . When comparing the evening with the morning blood sample a significant increase in haematocrit was found for the baseline and the CPAP night, but not for the follow-up night. Compared as morning to morning and evening to evening, the haematocrit remained statistically unchanged in the course of the study.

\section{Discussion}

ET-1 is a peptide hormone which is secreted predominantly by endothelial cells under the influence of stimuli such as ischaemia, hypoxia $[4,12]$, shear stress, as well as various receptor operated mechanisms [4]. Most of the produced ET-1 is released abluminally [4], a fact that could explain the extremely low concentrations found in the plasma. Human pulmonary circulation is an important site for both clearance and production of ET-1 [13] and contributes to the short plasma half-life of ET-1 of only 4-7 $\min [14]$.

The involvement of ET-1 in the pathogenesis of pulmonary hypertension $(\mathrm{PH})$ seems evident $[2,3]$, whereas a possible association with arterial hypertension remains controversial. Numerous studies examining the effects of endothelin antagonists or the interactions of ET-1 with blood pressure regulating hormones seem to indicate that

Table 4. - Haematocrit measurements

\begin{tabular}{lcccc}
\hline & Baseline & CPAP & $\begin{array}{c}\text { CPAP } \\
\text { follow-up }\end{array}$ & p-value* \\
\hline $\mathrm{n}$ & 29 & 20 & 15 & \\
$\begin{array}{c}\text { Haematocrit } \\
\text { evening \% }\end{array}$ & $40.7 \pm 0.8$ & $42.1 \pm 0.7$ & $43.1 \pm 0.7$ & 0.08 \\
$\begin{array}{c}\text { Haematocrit } \\
\text { morning \% } \\
\text { p-value }\end{array}$ & $41.7 \pm 0.7$ & $43.1 \pm 0.7$ & $42.8 \pm 0.7$ & 0.94 \\
\hline
\end{tabular}

*: p-values are from analysis of variance. CPAP: continuous positive airway pressure. 
ET-1 plays a role as a vasoconstrictor in peripheral resistance vessels and may contribute to blood pressure elevation. However, further studies are required to accumulate evidence for the involvement of endothelins in the mechanisms underlying human hypertension.

Epidemiological studies have shown an association between systemic hypertension and OSA independent of obesity, age and sex [7, 8]. Patients suffering from OSA present repetitive apnoeas and hypopnoeas which result in oxygen desaturations with arousals as well as increased sympathetic nerve activity, and all of these are thought to contribute to day-time hypertension [15-18]. It was also reported that OSA significantly raises the risk for cardiovascular events [19] and that an association independent of hypertension exists between OSA and endothelial dysfunction in the form of an attenuated endotheliumdependent vascular relaxation [20], suggesting a vascular pathogenetic link between OSA and systemic hypertension. Interestingly, ET-1 also seems to be involved in endothelial dysfunction, as its generation is augmented in various forms of vascular remodelling.

During sleep, patients with OSA undergo repetitive apnoeas followed by surges of pulmonary artery pressure (PAP). Whether OSA is independently related to PAP during day-time is not yet clear, however, $\mathrm{PH}$ is often seen in patients with OSA [21]. This association is particularly obvious in those patients with coexisting chronic airflow limitation [6], but also present in subjects in whom significant lung or heart disease was excluded [5].

The patients assessed in this study suffered from frequent intermittent hypoxaemia, which was hypothesized to be a cause for elevation of ET-1 plasma levels. However, venous ET-1 levels in the patients were not elevated compared to the control subjects and remained unchanged under CPAP-therapy, with drastically diminished episodes of hypoxaemia and arousal. Follow-up data yielded no significant changes.

As stimulation of the sympathetic nervous system, particularly during sleep, is often found in patients with OSA, and an interaction between the sympathetic stimulation and plasma levels of ET-1 may exist [22] this study investigated whether there is a link between catecholamines and ET- 1 levels. The findings of the noradrenaline and adrenaline plasma levels, however, revealed no correlation, either to ET-1 plasma levels or to the severity of the OSA as measured by the AHI. Nevertheless, a significant decrease of the noradrenaline plasma levels was found under long-term treatment with CPAP, which may cautiously be interpreted as a sign of attenuated sympathetic activation under CPAP therapy. Plasma noradrenaline concentrations are not ideal as a measure of sympathetic activation though. Only a fraction of neurally released noradrenaline appears in the plasma and does not reflect neurotransmitter release, but rather the balance between spillover and clearance.

This study could demonstrate a significant correlation between the mean arterial pressure and the severity of the OSA expressed as AHI or minimum $\mathrm{Sa}_{\mathrm{a}} \mathrm{O}_{2}$ during the overnight recording. A lack of blood pressure reduction during sleep was also found in patients with severe OSA. These findings are in accordance with a number of earlier studies [19].

The finding, that the MAP was not significantly reduced in either group taken individually under CPAP is probably due to a statistical problem, since both groups taken together presented a trend towards lower night-time values. Group 1, who exhibited a significant decrease in MAP from day to night without CPAP, is represented by only five members during the CPAP night, a fact that increases standard error, thus reducing statistical significance. Haematocrit levels, compared from morning to morning and evening to evening, remained statistically unchanged in the course of the study. This finding is in line with that of an earlier study [23] but at variance with another [24].

Compliance was rather low amongst the patients. The CPAP devices counted a mean running time of $4.1 \mathrm{~h}$ per night which may overestimate real use time.

So far, there has been only one study to assess circulating ET-1 levels in OSA [25]. The authors found a significantly higher level of ET-1 in patients with OSA compared to a healthy control group. This evidence is arguable though, since the control group was in no parameter matched to the patients and consisted of hospital and laboratory workers who were presumably younger than the patients. Furthermore, the determination of plasma ET-1 was performed only in the morning. Since the half-life of ET-1 in the plasma is only 4-7 min, as noted above, in order to show a relation between ET-1 levels and OSA it seems more appropriate to measure the concentration in the plasma during sleep, preferably shortly after an episode of hypoxaemia.

Most authors measured ET-1 plasma levels to be within the range of 1 to $5 \mathrm{pg} \cdot \mathrm{mL}^{-1}$, which is equivalent to about one tenth of the ones the current authors measured. The reason for this is that in those studies enzyme linked immunosorbent assay (ELISA) was used for ET-1 determination. The assay used in the current study is a radioimmunoassay which is known to produce results $\sim 10$ times higher than the ELISA. Since there is not yet any generally accepted standard method, results differ greatly between different studies.

In this study blood samples were obtained from an antecubital vein. The authors chose not to puncture an artery because in an earlier study no significant difference was found in ET-1 levels between the femoral artery and the femoral vein [26]. Also, the procedure of puncturing an artery is much more uncomfortable for the patients and seemed inappropriate for ethical reasons, as it involves a small risk of arterial thrombosis.

Because ET-1 is largely released abluminally towards the smooth muscle cells and binds to the $\mathrm{ET}_{\mathrm{A}}$ and $\mathrm{ET}_{\mathrm{B}}$ receptors it is unlikely that this portion of the ET-1 production has any effect on the plasma level. For example, arterial hypertension induced by deoxycorticosterone acetate (DOCA)-salt in rats was found to correspond with an increased vascular production of ET-1 in the presence of normal circulating levels of the peptide [27]. These facts indicate that plasma ET-1 level measurements are a poor reflection of the production and have to be interpreted with caution. Power calculation yielded a beta factor of $3.2 \%$ for testing of ET-1 level differences between patients and controls with a standard deviation (SD) of 10 $\mathrm{pg} \cdot \mathrm{mL}^{-1}$. The testing of differences between ET-1 levels after baseline and after the CPAP night, using an SD of 10 $\mathrm{pg} \cdot \mathrm{mL}^{-1}$, yielded a beta factor of $6.9 \%$. Thus, the power of the tests was sufficient enough to detect differences of $10 \mathrm{pg} \cdot \mathrm{mL}^{-1}$ or larger, whereas smaller differences could have remained undiscovered. 
More than half of the patients were on antihypertensive medication. Former studies showed that angiotensin converting enzyme inhibitors tended to decrease [28] and short acting vasodilators such as nitrates [28] tended to increase ET-1 concentrations whereas calcium antagonists [29] and $\beta$-blockers [30] showed no influence. Since ET-1 plasma levels in the medicated patients did not differ significantly from those without medication and none of the concerned medications were changed during the study, this factor can probably be neglected in the evaluation of the results.

The present study reveals that the plasma level of circulating endothelin-1 measured in a peripheral vein is not elevated in subjects with obstructive sleep apnoea. Continuous positive airway pressure therapy can attenuate nocturnal hypoxaemias and decrease noradrenaline circulating levels, but does not affect endothelin-1 plasma levels.

\section{References}

1. Yanagisawa M, Kurihara H, Kimura S, et al. A novel potent vasoconstrictor peptide produced by vascular endothelial cells. Nature 1988; 332: 411-415.

2. Stewart DJ, Levy RD, Cernacek P, Langleben D. Increased plasma endothelin-1 in pulmonary hypertension: marker or mediator of disease? Ann Intern Med 1991; 114: 464-469.

3. Giaid A, Yanagisawa M, Langleben D, et al. Expression of endothelin-1 in the lungs of patients with pulmonary hypertension. N Engl J Med 1993; 328: 1732-1739.

4. Lüscher TF, Wenzel RR. Endothelin and endothelin antagonists: pharmacology and clinical implications. In: Schroer K, Pace-Asciak CR, eds. Mediators in the cardiovascular system: regional ischemia. Basel, Switzerland, Birkhaeuser Verlag, 1995; pp. 237-253. Agents and Actions Supplements; vol. 45.

5. Sajkov D, Cowie RJ, Thornton AT, Espinoza HA, McEvoy RD. Pulmonary hypertension and hypoxemia in obstructive sleep apnoea syndrome. Am J Respir Crit Care Med 1994; 149: 416-422.

6. Laks L, Lehrhaft B, Grunstein RR, Sullivan CE. Pulmonary hypertension in obstructive sleep apnoea. Eur Respir J 1995; 8: 537-541.

7. Hla KM, Young TB, Bidwell T, Palta M, Skatrud JB, Dempsey J. Sleep apnoea and hypertension. A population-based study. Ann Intern Med 1994; 120: 382-388.

8. Carlson JT, Hedner JA, Ejnell H, Peterson LE. High prevalence of hypertension in sleep apnoea patients independent of obesity. Am J Respir Crit Care Med 1994; 150: 72-77.

9. Rechtschaffen A, Kales A. Manual of standardized terminology techniques and scoring system for sleep stages of human subjects. National Institutes of Health Publication, No. 204, 1968.

10. Quanjer PH, Tammeling GJ, Cotes JE, Pedersen OF, Peslin R, Yernault JC. Lung volumes and forced ventilatory flows. Official position of the European Respiratory Society. Eur Respir J 1993; 6 (Suppl. 16): 5-40.

11. Van der Boorn FAJ, Boosma F, Mann AJ, Schalekamp MADH. Determination of catecholamines in human plasma by high-performance liquid chromatography: comparison between a new method with fluorescence detection and an established method with electrochemical detection. J Chromatogr 1989; 487: 17-28.

12. Ferri C, Bellini C, De Angelis C, et al. Circulating endothelin-1 concentrations in patients with chronic hypoxia. J Clin Pathol 1995; 48: 519-524.
13. Dupuis J, Goresky CA, Stewart DJ. Pulmonary removal and production of endothelin in the anesthetized dog. $J$ Appl Physiol 1994; 76: 694-700.

14. Yanagisawa M, Inoue A, Takuwa Y, Mitsui Y, Kobayashi M, Masaki T. The human preproendothelin-1 gene: possible regulation by endothelial phosphoinositide turnover signaling. J Cardiovasc Pharmacol 1989; 13 (Suppl. 5): S13-S17.

15. Carlson JT, Hedner J, Elam M, Ejnell H, Sellgren J, Wallin BG. Augmented resting sympathetic activity in awake patients with obstructive sleep apnoea. Chest 1993; 103: 1763-1768.

16. Ringler J, Garpestad E, Basner RC, Weiss JW. Systemic blood pressure elevation after airway occlusion during NREM sleep. Am J Respir Crit Care Med 1994; 150: 1062-1066.

17. Brooks D, Homer RL, Kozar LF, Render-Teixeira CL, Phillipson EA. Obstructive sleep apnoea as a cause of systemic hypertension. Evidence from a canine model. $J$ Clin Invest 1997; 99: 106-109.

18. Hedner JA, Wilcox I, Laks L, Grunstein RR, Sullivan CE. A specific and potent pressor effect of hypoxia in patients with sleep apnoea. Am Rev Respir Dis 1992; 146: 12401245.

19. Stradling J, Davies RJ. Sleep apnoea and hypertensionwhat a mess! Sleep 1997; 20: 789-793.

20. Carlson JT, Rangemark C, Hedner JA. Attenuated endothelium-dependent vascular relaxation in patients with sleep apnoea. $J$ Hypertens 1996; 14: 577-584.

21. Weitzenblum E, Krieger J, Apprill M, et al. Daytime pulmonary hypertension in patients with obstructive sleep apnoea syndrome. Am Rev Respir Dis 1988; 138: 345349.

22. Cody RJ, Haas GJ, Binkley PF, Capers Q, Kelley R. Plasma endothelin correlates with the extent of pulmonary hypertension in patients with chronic congestive heart failure. Circulation 1992; 85: 504-509.

23. Cahan C, Decker MJ, Arnold JL, Goldwasser E, Strohl KP. Erythropoietin levels with treatment of obstructive sleep apnoea. J Appl Physiol 1995; 79: 1278-1285.

24. Krieger J, Sforza E, Delanoe C, Petiau C. Decrease in haematocrit with continuous positive airway pressure treatment in obstructive sleep apnoea patients. Eur Respir $J$ 1992; 5: 228-233.

25. Saarelainen S, Seppala E, Laasonen K, Hasan J. Circulating endothelin-1 in obstructive sleep apnoea. Endothelium 1997; 5: 115-118.

26. Tsutamoto T, Wada A, Maeda Y, Adachi T, Kinoshita M. Relation between endothelin-1 spillover in the lungs and pulmonary vascular resistance in patients with chronic heart failure. J Am Coll Cardiol 1994; 23: 1427-1433.

27. Lüscher TF. The endothelium in hypertension: bystander, target or mediator? J Hypertens Suppl 1994; 12 (Suppl. 10): S105-S116.

28. Noll G, Wenzel RR, de Marchi S, Shaw S, Lüscher TF. Differential effects of captopril and nitrates on muscle sympathetic nerve activity in volunteers. Circulation 1997; 95: 2286-2292.

29. Yang Z, Bauer E, von Segesser L, Stulz P, Turina M, Luscher TF. Different mobilization of calcium in endothelin-1-induced contractions in human arteries and veins: effects of calcium antagonists. J Cardiovasc Pharmacol 1990; 16: 654-660.

30. Cosenzi A, Sacerdote A, Bocin E, et al. Neither physical exercise nor alpha 1- and beta-adrenergic blockade affect plasma endothelin concentrations. Am J Hypertens 1996; 9: 819-822. 